Document downloaded from:

http://hdl.handle.net/10251/66100

This paper must be cited as:

Nafria, R.; Ramirez De La Piscina, P.; Homs, N.; Ramon Morante, J.; Cabot, A.; Díaz Morales, UM.; Corma Canós, A. (2013). Embedding catalytic nanoparticles inside mesoporous structures with controlled porosity: Au@TiO2. Journal of Materials Chemistry. 1(45):14170-14176. doi:10.1039/c3ta13346j.

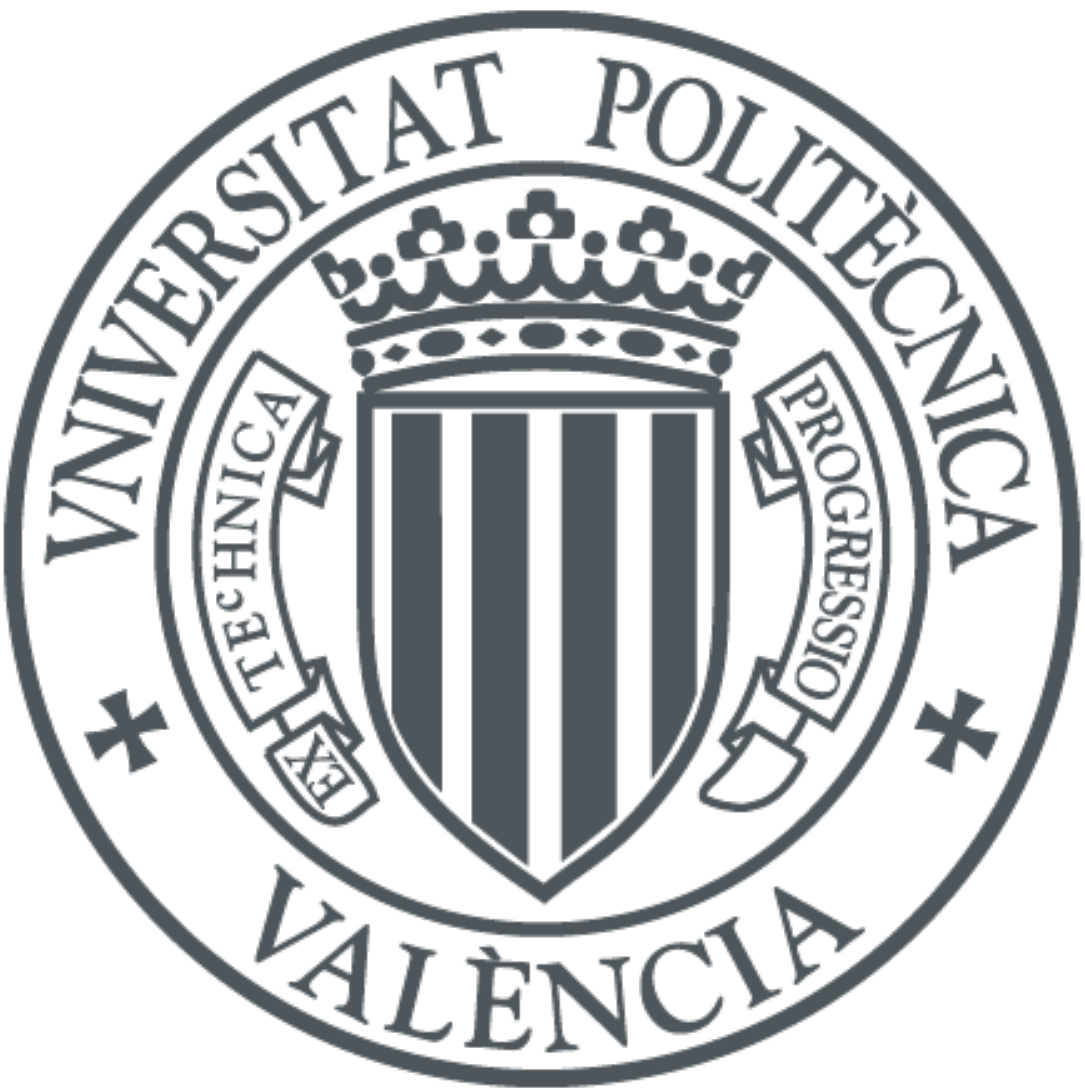

The final publication is available at

http://dx.doi.org/10.1039/c3ta13346j

Copyright Royal Society of Chemistry

Additional Information 


\title{
Embedding catalytic nanoparticles inside mesoporous structures with controlled porosity: Au@ $\mathrm{TiO}_{2}$
}

\author{
Raquel Nafria, ${ }^{a}$ Pilar Ramírez de la Piscina, ${ }^{b}$ Narcís Homs, ${ }^{a, b}$ Joan Ramón Morante, ${ }^{a, c}$ Andreu Cabot, $* a, c$ \\ Urbano Diaz, Avelino Corma*,
}

\author{
${ }_{5}$ Received (in $\left.X X X, X X X\right)$ Xth $X X X X X X X X X 20 X X$, Accepted $X$ th $X X X X X X X X X 20 X X$ \\ DOI: $10.1039 / b 000000 x$
}

The hability to produce catalytic nanoparticles with controlled properties is key to develop and produce heterogeneous catalysts with optimized activity and selectivity. Not less important is to maximize the nanoparticle dispersion over high area supports maintaining 10 their optimized properties. Here we detail a general procedure to produce heterogeneous catalysts containing a large surface area mesoporuos support and highly dispersed catalytic nanoparticles with controlled properties. We exemplify the developed method using colloidal gold nanocrystals as the catalytically active phase and titanium oxide as the paradigmatic support. Our synthetic strategy is based on the formation of an inorganic15 organic hybrid mesoporous material from the surface of the colloidal nanocrystals. A variety of organic spacers allows tuning the final porosity of the support. The good accessibility of the active catalytic sites in these materials is demonstrated by high $\mathrm{CO}$ oxidation conversion values.

\section{${ }_{20}$ Introduction}

When preparing heterogeneous catalysts formed by metal nanoparticles dispersed on high area oxide supports, one aims to maximize the nanoparticle dispersion and its most active and selective facets, to optimize its size, and in some cases to enhance 25 the interaction strength between the metal nanoparticle and the oxide support. A first step towards maximizing the active phase dispersion is the use of mesoporous supports with large surface areas. The challenge arrives when attempting to disperse the active catalytic phase in such highly porous structures. 30 Conventional impregnation methods hardly allow to take full advantage of the enormous surface areas of mesoporous supports. Moreover, impregnation methods do not provide the level of control over the nanoparticle properties required to optimize their catalytic performance. A solution towards optimizing 35 nanoparticle properties can be found in colloidal synthesis routes, which have been demonstrated successful in preparing nanoparticles with a high level of control over size, geometry, phase, and composition. ${ }^{[1-5]}$ However, the dispersion of these nanoparticles over oxide supports, especially those with large 40 surface areas and small pores is an extremely challenging task. Recently, a new synthetic strategy to produce mesoporous silica matrices with embedded but accessible gold nanoparticles has been reported. ${ }^{[1,6-9]}$ This strategy involves the formation of threecomponent metal-organic-inorganic structures by means of the

This journal is (C) The Royal Society of Chemistry [year]
${ }_{45}$ polymerization of organosilica units anchored at the surface of colloidal metal nanoparticles.

In the present study, we generalize this synthetic procedure to the preparation of dispersed and accessible metal nanoparticles embedded within transition metal mesoporous matrices having 50 controlled porosity. We exemplify the method using colloidal gold nanocrystals as the active catalytic phase and titanium oxide as the model support. Aromatic carboxylates derivates were used as physical spacers between titanium centers in the initial inorganic-organic hybrid framework ${ }^{[10-12]}$. We demonstrate the 55 accessibility of the catalytic nanoparticles embedded in $\mathrm{TiO}_{2}$ mesoporous matrices by measuring the $\mathrm{CO}$ oxidation at low temperature and analyzing the coordination sites by means of DRIFT spectroscopy.

\section{${ }_{60}$ Experimental section}

Preparation of gold nanoparticles: Gold nanoparticles were prepared following the procedure reported by Budroni and Corma. ${ }^{[6,7]}$ In a typical synthesis, $0.2 \mathrm{ml} \mathrm{H}_{2} \mathrm{O}, 23 \mathrm{ml}$ isooctane and $1 \mathrm{~g}$ sodium bis(2-ethylhexyl)sulfosuccinate (AOT) were ${ }_{65}$ stirred for $20 \mathrm{~min}$. Then, $1.2 \mathrm{ml}$ of a $0.1 \mathrm{M} \mathrm{HAuCl}_{4}$ aqueous solution was added to the emulsion. After 15 min stirring, a mixture of $55.7 \quad \mu \mathrm{l}$ 1-dodecanethiol (DT) and $3.4 \quad \mu \mathrm{l}$ mercaptopropyltrimethoxysilane (MPMS) was added. Then, 100 $\mu l$ of hydrazine was injected to reduce the gold ions into metallic 70 gold nanocrystals. After 3 hours of stirring, the solution was left to rest overnight. The precipitate was separated from the clear 
solution by decantation. Nanoparticles were filtered using a Whataman nylon membrane $0.45 \mu \mathrm{m}$, washed with toluene, and finally re-dispersed using an ultrasonic bath.

Preparation of gold-titania mesoporous structures,

${ }_{5} \mathbf{A u} @ \mathbf{T i O}_{2}$ : $40 \mathrm{ml}$ of a solution containing $\mathrm{Au}$ nanoparticles in ethanol $\left(3 \cdot 10^{-3} \mathrm{M}\right)$ prepared following the previous procedure, were added to a solution containing $6.9 \mathrm{ml}$ of titanium (IV) ethoxide and $1 \mathrm{ml}$ of $\mathrm{H}_{2} \mathrm{O}$. After stirring during 30 minutes at room temperature, the solution became a gel that slowly

10 converted into a white powder. The obtained powder was dried overnight at $100{ }^{\circ} \mathrm{C}$ in a vacuum oven and afterward calcined in air at $450{ }^{\circ} \mathrm{C}$ for 4 hours to remove the remaining organic molecules.

Preparation of gold-spacer-titania mesoporous structures, $15 \mathbf{A u} @ \mathbf{T i O}_{2}$ (x): $11 \mathrm{ml}$ of a toluene solution containing $\mathrm{Au}$ nanoparticles $(0.01 \mathrm{M})$ prepared following the above procedure were added to a solution containing $2.6 \mathrm{ml}$ titanium (IV) ethoxide and $47 \mu \mathrm{l}$ of $\mathrm{H}_{2} \mathrm{O}$. This mixture was then added to $100 \mathrm{ml}$ of a diethylformamide solution containing the appropriate amount of 20 the selected carboxylic acid (molar ratio $\left.\mathrm{Ti}(\mathrm{OEt})_{4}\right) /$ carboxylic acid $=1.35$ ). The concentration of the organic spacer was selected taking into account the results obtained in a previous work. ${ }^{[10]}$ The final solution was vigorously stirred and heated to $120{ }^{\circ} \mathrm{C}$ under Ar for $12 \mathrm{~h}$. The gel-like precipitate obtained was filtered

25 and washed with toluene. The precipitate was dried in a vacuum oven for $48 \mathrm{~h}$ at $160{ }^{\circ} \mathrm{C}$. Temperature was afterward raised to 180 ${ }^{\circ} \mathrm{C}$ and maintained there for $6 \mathrm{~h}$. The obtained powder was calcined in air at $450{ }^{\circ} \mathrm{C}$ for $4 \mathrm{~h}$ to remove organic molecules. ${ }^{[10]}$ Scheme 1 represents the synthesis method. Table 1 details the 30 carboxylic acid used and the nomenclature of the gold-spacertitania mesoporous structure prepared.

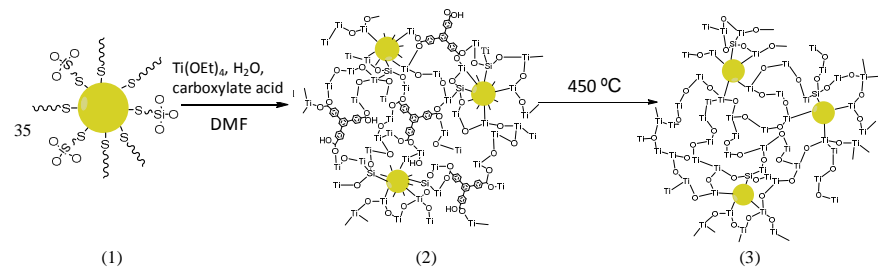

Scheme 1. Synthesis procedure. 1) gold nanoparticles stabilized 40 with 1-dodecanethiol (DT) and mercaptopropyltrimethoxysilane (MPMS); 2) hybrid organic-inorganic network containing the gold nanoparticles and using 1,3,5-Tris(4-carboxyphenyl)benzene as the physical spacer; 3) final mesoporous matrices $\mathrm{Au} @ \mathrm{TiO}_{2}$.

\section{${ }_{45}$ Materials characterization:}

Crystallographic phases were characterized using powder x-ray diffraction (XRD). XRD patterns were obtained on a Bruker D8 automated diffractometer, equipped with a primary monochromator and LynxEye detector and using $\mathrm{Cu} \mathrm{K} \alpha$

50 radiation. The instrument resolution was $0.05^{\circ}$ in $2 \theta$, the studied range was from $4-80^{\circ}$ and the acquisition time for each sample was set to $1 \mathrm{~h} 20 \mathrm{~min}$.

The specific surface area of the materials was determined by $\mathrm{N}_{2}$ adsorption at $77 \mathrm{~K}$ using a Tristar II 3020 Micromeritics system. ${ }_{55}$ Specific areas were calculated using the Brunauer- Emmet-Teller
(BET) method. The BET specific surface area was obtained from the analysis of the adsorption at $\mathrm{P} / \mathrm{Po}=0.999$.

Thermogravimetric analyses (TGA) were performed in the temperature range $30-800{ }^{\circ} \mathrm{C}$ at a heating rate of $10^{\circ} \mathrm{C} / \mathrm{min}$ under 60 air using a Perkin Elmer TGA4000.

Metal contents were determined using optical emission spectroscopy by means of inductively coupled plasma (ICP) on a Perkin Elmer Optima 3200 RL system.

Elemental analyses were performed using an elemental organic ${ }_{65}$ analyzer Thermo EA 1108, working under $120 \mathrm{ml} / \mathrm{min}$ helium flow, the combustion furnace at $1000{ }^{\circ} \mathrm{C}$, the chromatografic column oven at $60^{\circ} \mathrm{C}$, and $10 \mathrm{ml}$ oxygen loop at $100 \mathrm{kPa}$.

Transmission electron microscopy (TEM) micrographs were obtained using a JEOL JEM-2100.

70 FT-IR spectra were recorded on a Bruker IR ALPHA in the range $4000-400 \mathrm{~cm}^{2}$.

Table 1. Nomenclature of the gold-spacer-titania mesoporous structures prepared. 75

\begin{tabular}{ccc}
\hline Sample name & Carboxylate & $\begin{array}{c}\text { Carboxylate } \\
\text { structure }\end{array}$ \\
$\mathrm{Au} @ \mathrm{TiO}_{2}(\mathrm{t})$ & $\begin{array}{c}\text { Terephtalic acid } \\
\mathrm{Au} @ \mathrm{TiO}_{2}(\mathrm{n})\end{array}$ & $\begin{array}{c}\text { Naphthalenedicarboxylic } \\
\text { acid }\end{array}$ \\
$\mathrm{TiO}_{2}$ (b) & $\begin{array}{c}1,3,5-\mathrm{Tris}(4- \\
\text { carboxyphenyl)benzene }\end{array}$
\end{tabular}

Catalytic activity:

${ }_{90}$ Catalytic tests were carried out in a Microactivity-Reference unit (PID Eng\&TECH) in the temperature range $25-250{ }^{\circ} \mathrm{C}$ under atmospheric pressure. $100 \mathrm{mg}$ of catalyst was mixed with inactive $\mathrm{SiC}$ (Prolabo, $0.21 \mathrm{~mm}$ ) and placed in a tubular fixed-bed reactor (305 mm long, $9 \mathrm{~mm}$ i.d., 316-L stainless steel) up to a catalytic 95 volume of $0.5 \mathrm{ml}$. The temperature was measured by a thermocouple in direct contact with the catalytic bed. A mixture of $8.1 \% \mathrm{CO}$, air $\left(\mathrm{CO} / \mathrm{O}_{2}\right.$ molar ratio $=2, \mathrm{~N}_{2}$ was used as a internal standard) and balanced with $\mathrm{He}$, was feed to the reactor. A gas hourly space velocity $(\mathrm{GHSV}=$ volumetric inlet gas 100 flow/catalyst volume bed) of $6700 \mathrm{~h}^{-1}$ was used. The products were analysed on-line with a Varian 450-GC gas chromatograph equipped with a methanizer and TCD and FID detectors. Catalytic tests, related with the water gas shift (WGS) reaction, were carried out in the same equipment in the temperature range $105250-450{ }^{\circ} \mathrm{C}$ under atmospheric pressure. $100 \mathrm{mg}$ of catalyst was mixed with inactive $\mathrm{SiC}$ (Prolabo, $0.21 \mathrm{~mm}$ ) and placed in a tubular fixed-bed reactor (305 mm long, $9 \mathrm{~mm}$ i.d., 316-L stainless steel) up to a catalytic volume of $0.5 \mathrm{ml}$. The temperature was measured by a thermocouple in direct contact 110 with the catalytic bed. A mixture of $7.5 \% \mathrm{CO}$, vapor $\left(\mathrm{CO} / \mathrm{H}_{2} \mathrm{O}\right.$ 
molar ratio $=2.6$ ) and balanced with Ar was feed into reactor using a GHSV $=9965 \mathrm{~h}^{-1}$.

The CO oxidation reaction was monitored by means of diffuse reflectance infrared spectroscopy (DRIFT) in a Nicolet Magna-IR 5750 FTIR spectrometer equipped with a liquid-nitrogen-cooled MCT detector and a Spectra Tech Inc. catalytic DRIFT chamber. The outlet of the DRIFT chamber was connected on-line through a capillary tube to a Balzers instrument (QME 200) equipped with a quadrupole mass spectrometer, which had been previously 10 calibrated to monitor the evolution of the different potential products. A mixture of $9.87 \% \mathrm{CO} / \mathrm{He}$ and $10.03 \% \mathrm{O}_{2} / \mathrm{He}$ in a molar ratio $\mathrm{CO} / \mathrm{O}_{2}=2$ molar and balanced with $\mathrm{He}$, in a total flow of $30 \mathrm{ml} / \mathrm{min}$, was feed into the catalytic DRIFT chamber.

\section{${ }_{15}$ Results and discussions}

Gold nanoparticles stabilized with DT and MPMS were produced following the procedure reported by Budroni and Corma. ${ }^{[6]} \mathrm{A}$ representative TEM micrograph of the Au nanoparticles and its corresponding size distribution histogram are displayed in Figure 20 1a. The average size of the gold nanoparticles prepared and used in this work was $2.1 \pm 0.5 \mathrm{~nm}$.
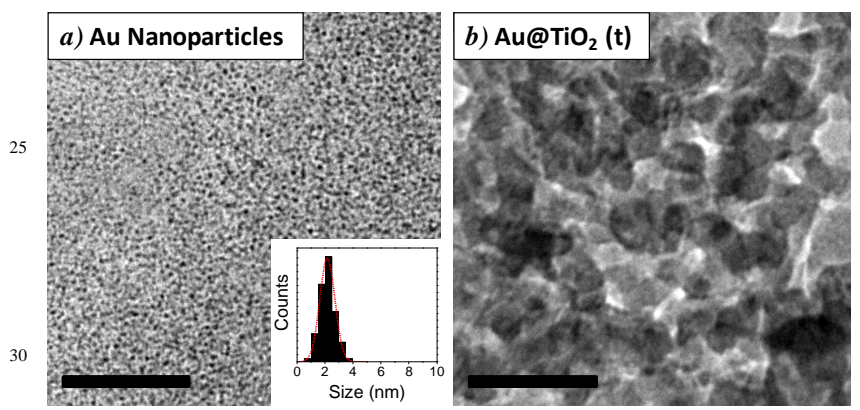

Figure 1. a) TEM micrographs of Au nanoparticles with average size of $2 \mathrm{~nm}$. Inset shows the histogram of the particle size distribution. B) TEM micrograph of the calcined $\mathrm{Au} @ \mathrm{TiO}_{2}(\mathrm{t})$ 35 material. Scale bars correspond to $50 \mathrm{~nm}$.

Au-organic-Ti materials were prepared from an ethanol solution of DT- and MPMS-caped Au nanoparticles and titanium (IV) ethoxide. Each surface ligand, DT and MPMS, plays a key role 40 during the formation of the hybrid material. The MPMS alkoxysilane groups promote the hydrolysis and condensation of $\mathrm{Ti}(\mathrm{OEt})_{4}$ around the gold NP and provide a link between the metal and the titania. On the other hand, inert DT alkane chains behave as physical spacers between the particles and the titania 45 shell. In nanoparticles containing only MPMS, a silica layer is formed around the gold nanoparticle, making its surface inaccessible for catalysis. On the other hand, without MPMS the titania mesoporous structure would grow independently of gold nanoparticles. ${ }^{[6]}$

${ }_{50}$ To further control the $\mathrm{Ti}-\mathrm{Ti}$ and $\mathrm{Ti}-\mathrm{Au}$ distance in the Auorganic-Ti mesoporous structures, we used rigid carboxylic acid as spacers in between titanium centers (Scheme 1). Three carboxylates with different lengths were tested in the present work: terephtalic acid, 2,6-naphthalenedicarboxylic acid and 55 1,3,5-tris(4-carboxyphenyl)benzene. The use of such organic compounds initially resulted in highly porous organic-inorganic hybrid frameworks resembling those of metal organic frameworks. ${ }^{[13-15]}$

Figure 2 shows the IR spectra of the isolated free acid (Fig. 2A) 60 and the hybrid material (Fig. 2B). The carboxylate stretching frequencies are between $1600-1380 \mathrm{~cm}^{-1}$. Bands around $1400 \mathrm{~cm}^{-}$

1 correspond to symmetric stretching modes $\gamma_{\text {sym }}$ and bands between $1600-1500 \mathrm{~cm}^{-1}$ are assigned to asymmetric modes $\gamma_{\text {asym. }}$. The difference between carboxylate stretching frequencies $\Delta$ ${ }_{65}=\gamma_{\text {asym }}-\gamma_{\text {sym }}$ of the ionic therephtalic structure is around $\Delta=177 \mathrm{~cm}^{-}$ ${ }^{1}{ }^{[10]}$ We suppose similar values for the other ionic structures. We determined the bonding mode between the carboxylic acids groups and titanium centers in Au-organic-Ti structures by measuring $\Delta=\gamma_{\text {asym }}-\gamma_{\mathrm{sym}}$. While monodentate complexes have 70 higher $\Delta$ values than the ionic structure, in bidentate-bridging modes $\Delta$ values are lower but close to the ionic value, and bidentate chelating modes exhibit much lower $\Delta$ values than the corresponding ionic structure. ${ }^{[10,16]}$ The frequency separations compiled in Table 2 suggests that terephthale and 1,3,5-tris(475 carboxyphenyl)benzene ligands were bonded to titanium as a monodentate and bidentate-chelating mode. However, 2,6naphthalenedicarboxylic was bonded in the bidentate-bridging and chelating bridging mode.
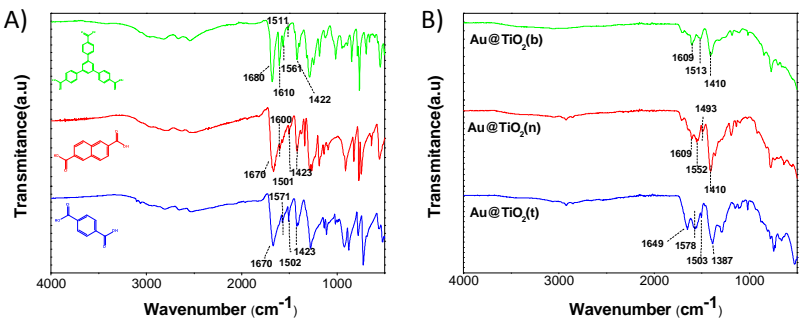

C)
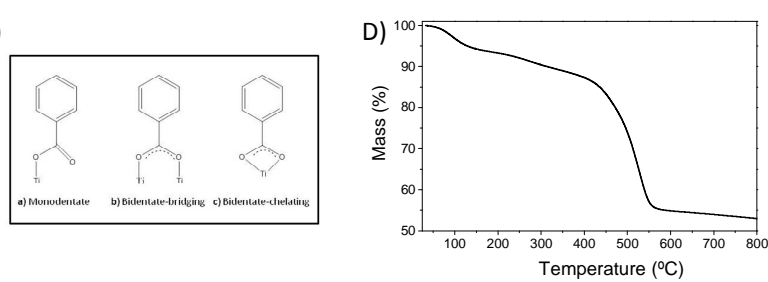

${ }_{80}$ Figure 2. IR spectra of the isolated free acid (a) and the hybrid material (b). c) carboxylate coordination modes. d) Thermogravimetric profile of the $\mathrm{Au} @ \mathrm{TiO}_{2}(\mathrm{t})$ mesoporous materials.

Table 2. Difference stretching frequencies of the isolated free 85 acid and the hybrid material.

\begin{tabular}{cccc}
\hline Carboxylate & \multicolumn{2}{c}{$\Delta=\gamma_{\mathrm{asym}-\gamma_{\mathrm{sym}} \mathrm{cm}^{-1}}$} & Bonding mode \\
& Free acid & $\begin{array}{c}\text { Hybrid } \\
\text { material }\end{array}$ & \\
\hline Terephtalic & 247 & $199-116$ & Monodentate-bidentate \\
$\begin{array}{c}\text { 2,6-Naphthalenedicarboxylic } \\
\text { 1,3,5-Tris(4- } \\
\text { carboxyphenyl)benzene }\end{array}$ & 247 & $142-83$ & Bidentate-chelating \\
& 258 & $191-103$ & Monodentate-bidentate
\end{tabular}

To determine the temperature required for organic removal, thermogravimetry analyses were conducted. Samples were heated at a rate of $10{ }^{\circ} \mathrm{C} \cdot \mathrm{min}^{-1}$ from room temperature to $800{ }^{\circ} \mathrm{C}$ in air 
(Figure 2d). Three weight loss steps were detected in most samples. The first weight loss step, in the range from 50 to 200 ${ }^{\circ} \mathrm{C}$, was associated with the evaporation of adsorbed water and weakly bonded solvent molecules. A second weight loss step, in 5 the range $200-400{ }^{\circ} \mathrm{C}$, was associated with the desorption of residual diethylformamide and interstitial water. The last step, starting at $450{ }^{\circ} \mathrm{C}$, corresponds to the pirolysis of the organic molecules, such as DT, MPMS and the organic spacers.

Elemental analysis showed a calcination treatment at $450{ }^{\circ} \mathrm{C}$ 10 during $4 \mathrm{~h}$ to be sufficient to totally remove the organic spacers. Therefore all the materials were calcined at $450{ }^{\circ} \mathrm{C}$ during 4 hours in air. The powder obtained was white for the samples with no $\mathrm{Au}$ and reddish-violet for the $\mathrm{Au} @ \mathrm{TiO}_{2}$ samples. ICP revealed the $\mathrm{Au}$ content after calcination to be around $1 \%$ for all samples 15 prepared.

Figure $1 \mathrm{~b}$ displays a TEM micrograph of the $\mathrm{Au} @ \mathrm{TiO}_{2}(\mathrm{t})$ mesoporous material finally obtained. Embedded $\mathrm{Au}$ nanoparticles were hardly seen due to their small size, high dispersion and relatively low concentration. However, few large $20 \mathrm{Au}$ nanoparticles independent to the $\mathrm{TiO}_{2}$ matrix were also observed. These large Au particles may be originated from initial gold aggregates which were not properly functionalized and thus were not embedded inside the $\mathrm{TiO}_{2}$ structure.
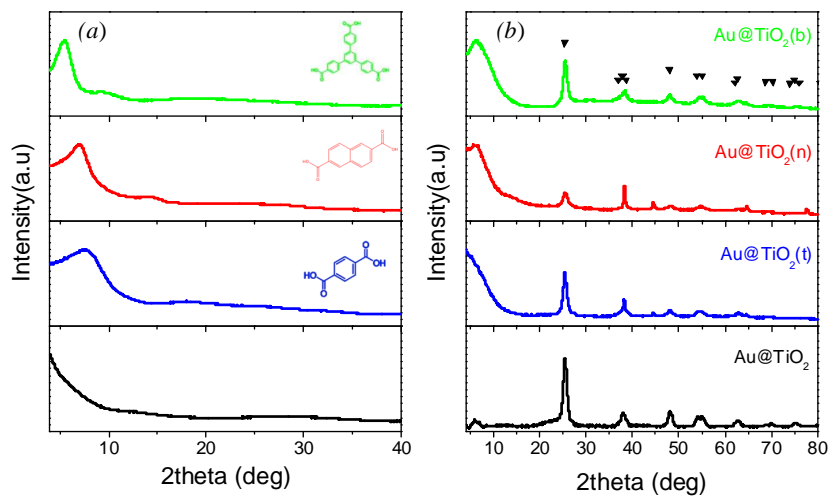

${ }_{25}$ Figure 3. X-ray diffraction patterns from the different $\mathrm{Au} @ \mathrm{TiO}_{2}$ mesoporous structures before (a) and after (b) the calcination treatment. The peaks corresponding to the anatase phase are marked as a reference.

30 Figure 3 shows the XRD patterns of the Au-spacer-Ti mesoporous materials initially obtained. No diffraction peak from the titania crystallographic structure was detected in the asprepared materials, proving its amorphous nature. However, the presence of $\mathrm{x}$-ray reflections at low angles indicated some degree 35 of structural organization at the nanometer scale. The diffraction peaks of the Au-spacer-Ti materials were shifted to lower angles with increasing the size of the organic carboxylate. Table 3 displays the d-spacing values calculated using the Bragg law. The increase of the d-spacing with the size of the carboxylate 40 molecule correlates well with the picture of Ti atoms separated by the different organic linkers.

With the calcination treatment the titania support crystallized into the anatase phase (JCPDS 21-1272, Figure 3b). When using organic spacers, a small peak at $30.8^{\circ}$ corresponding to the
45 brookite phase was also identified. The $\mathrm{TiO}_{2}$ crystallite size was estimated at $9-10 \mathrm{~nm}$ from the full width at half maximum of the (011) peak by Scherrer's equation. ${ }^{[17]}$ This reduced particle size potentially favor the catalytic performance of the material, as it increases the density of metal-support active-sites. ${ }^{[1,18-20]}$. 50

Table 3. Surface area before and after calcination and position of the main XRD peak of the as-prepared sample.

\begin{tabular}{|c|c|c|c|c|c|}
\hline \multirow[b]{2}{*}{$\begin{array}{l}\text { Sample } \\
\text { name }\end{array}$} & \multirow[b]{2}{*}{ Carboxylate } & \multirow{2}{*}{$\begin{array}{c}\text { XRD } \\
\text { spacing } \\
d(n m)\end{array}$} & \multicolumn{2}{|c|}{ Surface area $\left(\mathrm{m}^{2} / \mathrm{g}\right)$} & \multirow[b]{2}{*}{$\begin{array}{l}\text { Pore } \\
\text { size(Å) }\end{array}$} \\
\hline & & & $\begin{array}{c}\text { As- } \\
\text { prepared }\end{array}$ & Calcined & \\
\hline $\mathrm{TiO}_{2}$ & - & - & 552 & 64 & 53 \\
\hline $\mathrm{TiO}_{2}(\mathrm{t})$ & Terephtalic acid & 1.14 & 226 & 85 & 155 \\
\hline $\mathrm{TiO}_{2}(\mathrm{n})$ & $\begin{array}{l}\text { 2,6-naphthalenedicarboxylic } \\
\text { acid }\end{array}$ & 1.24 & 176 & 153 & 160 \\
\hline $\mathrm{TiO}_{2}(\mathrm{~b})$ & $\begin{array}{c}\text { 1,3,5-Tris(4- } \\
\text { carboxyphenyl)benzene }\end{array}$ & 1.61 & 341 & 180 & 42 \\
\hline $\mathrm{Au} @ \mathrm{TiO}_{2}$ & - & - & 349 & 89 & 55 \\
\hline $\mathrm{Au} @ \mathrm{TiO}_{2}(\mathrm{t})$ & Terephtalic acid & 1.13 & 293 & 109 & 280 \\
\hline $\mathrm{Au} @ \mathrm{TiO}_{2}(\mathrm{n})$ & $\begin{array}{l}\text { 2,6-Naphthalenedicarboxylic } \\
\text { acid }\end{array}$ & 1.37 & 183 & 178 & 328 \\
\hline $\mathrm{Au} @ \mathrm{TiO}_{2}$ (b) & $\begin{array}{c}\text { 1,3,5-Tris(4- } \\
\text { carboxyphenyl)benzene }\end{array}$ & 1.90 & 314 & 145 & 514 \\
\hline
\end{tabular}

Figure 4 shows the adsorption-desorption isotherm $\mathrm{N}_{2}$ cycles of ${ }_{55}$ the materials produced. The specific surface area of the asprepared Au-spacer-Ti mesoporous materials was in the range between 150 and $350 \mathrm{~m}^{2} / \mathrm{g}$. They showed type IV-H1 adsorptiondesorption isotherm cycles. Their porous contribution was essentially mesoporous, and they displayed broad BJH pore size ${ }_{60}$ distributions (Figure 4c, Supporting Information). The asprepared Au-Ti materials, with no spacer, typically displayed BET surface areas close to $350 \mathrm{~m}^{2} \mathrm{~g}^{-1}$ (Table 3) and type IV-H4 adsorption-desorption isotherms. $\mathrm{TiO}_{2}$ materials produced in the same way but without $\mathrm{Au}$ nanoparticles were characterized by 65 larger BET surface areas, above $550 \mathrm{~m}^{2} / \mathrm{g}$. These samples, having no gold and no spacer, presented type I physisorption isotherms, characteristic of microporous materials. ${ }^{[21,22]}$
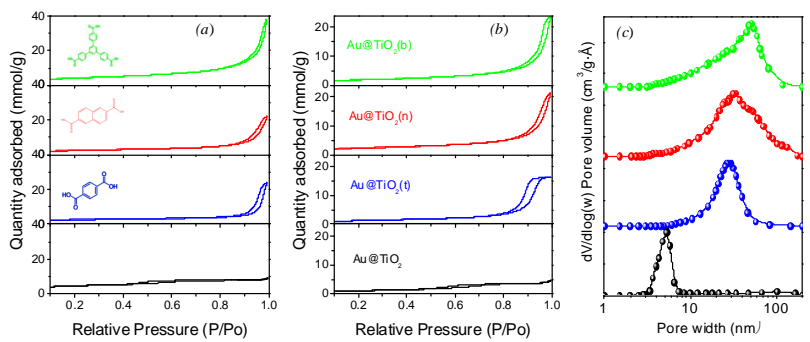

70 Figure 4. a), b): Adsorption/desorption isotherm cycles from the different $\mathrm{Au} @ \mathrm{TiO}_{2}$ mesoporous structures before (a) and after (b) the calcination treatment. c) BJH pore size distribution of the materials after calcination.

75 After calcination, the isotherms of all $\mathrm{Au} @ \mathrm{TiO}_{2}$ materials conserved the characteristic type IV cycles corresponding to mesoporous materials. However, a decrease of the surface area was obtained. Larger spacers had associated smaller surface area decreases, being the largest surface area decrease observed for the 80 materials with no organic spacer. We believe that the higher thermal stability of the larger carboxylate molecules more 
effectively prevented the mesoporous structure to collapse. This is consistent with the picture of organic spacer as effective structural directors.

Owing to its largest surface area, we selected the catalyst ${ }_{5} \mathrm{Au} @ \mathrm{TiO}_{2}(\mathrm{~b})$, prepared using 1,3,5-tris(4-carboxyphenyl)benzene acid as spacer, to compare the catalytic activity of embedded $\mathrm{Au} @ \mathrm{TiO}_{2}$ materials with that of impregnated samples. The impregnated $\mathrm{Au} / \mathrm{TiO}_{2}$ sample was prepared by impregnating a mesoporous $\mathrm{TiO}_{2}$ materials obtained using the 1,3,5-tris(410 carboxyphenyl)benzene spacer with $1 \%$ of $\mathrm{Au}: \mathrm{Au} / \mathrm{TiO}_{2}$ (b). As a reference, we also measured the catalytic performance of $\mathrm{Au} @ \mathrm{TiO}_{2}$ without spacer and that of the $\mathrm{TiO}_{2}$ sample with no gold, $\mathrm{TiO}_{2}(\mathrm{~b})$.

The materials catalytic activity was tested through the $\mathrm{CO}$ 15 oxidation reaction in the temperature range from $25^{\circ} \mathrm{C}$ to $250{ }^{\circ} \mathrm{C}$ (Figure 5). ${ }^{[23-28]}$ At each temperature, the system was allowed to stabilize during $10 \mathrm{~min}$. $\mathrm{Au} @ \mathrm{TiO}_{2}$ (b) showed $\mathrm{CO}$ to $\mathrm{CO}_{2}$ conversions above $80 \%$ at $50{ }^{\circ} \mathrm{C}$ and close to $100 \%$ at temperatures above $100{ }^{\circ} \mathrm{C}$. The sample with no spacer showed 20 lower catalytic conversion. Au@ $\mathrm{TiO}_{2}$ showed $25 \% \mathrm{CO}$ to $\mathrm{CO}_{2}$ conversion at $50{ }^{\circ} \mathrm{C}$ and above $70 \%$ at $250{ }^{\circ} \mathrm{C}$. These results probed the presence and accessibility of nanometric and active gold nanoparticles within the $\mathrm{Au} @ \mathrm{TiO}_{2}(\mathrm{~b})$ and $\mathrm{Au} @ \mathrm{TiO}_{2}$ mesoporous materials and confirmed that the use of spacers 25 increased the accessibility of the catalytic materials inside the $\mathrm{TiO}_{2}$ network. On the contrary, $\mathrm{TiO}_{2}(\mathrm{~b})$ and impregnated $\mathrm{Au} / \mathrm{TiO}_{2}$ (b) samples showed a very reduced catalytic activity in the temperature range tested, most probably due to the limited availability of metal catalyst nanoparticles with small enough 30 sizes.
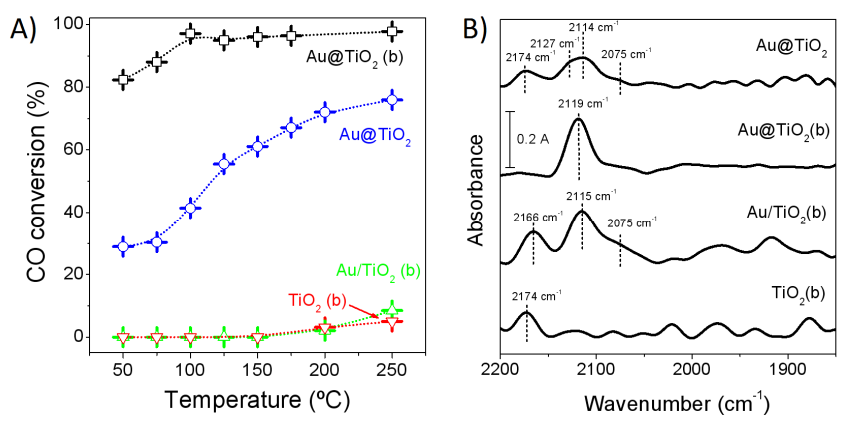

Figure 5. A) $\mathrm{CO}$ conversion as a function of temperature for pure $\mathrm{TiO}_{2}$ support, impregnated $\mathrm{Au} / \mathrm{TiO}_{2}(\mathrm{~b})$, embedded $\mathrm{Au} @ \mathrm{TiO}_{2}$ and $\mathrm{Au} @ \mathrm{TiO}_{2}(\mathrm{~b})$. B) DRIFT spectra under CO oxidation reaction

We further studied the materials catalytic performance using DRIFT spectroscopy coupled to mass spectrometry to follow the evolution of adsorbed species. Before the $\mathrm{CO}-\mathrm{O}_{2}$ adsorption experiment, samples were treated at $150{ }^{\circ} \mathrm{C}$ in oxygen 40 atmosphere. At this temperature, $\mathrm{CO}$ and oxygen were introduced into the DRIFT chamber. After 1h, the reaction was quenched by introducing $\mathrm{He}$ into the chamber and quickly cooling the material to $25{ }^{\circ} \mathrm{C}$. During cooling, free $\mathrm{CO}$ and $\mathrm{CO}_{2}$ progressively disappeared but bonded $\mathrm{CO}$ remained attached to the material ${ }_{45}$ surface. Figure $5 \mathrm{~b}$ shows the DRIFT spectra after quenching. The $\mathrm{TiO}_{2}$ (b) support showed a unique band at $2174 \mathrm{~cm}^{-1}$ assigned to $\mathrm{CO}$ adsorbed to $\mathrm{Ti}^{\mathrm{IV}}$ sites on the anatase surface. ${ }^{[29-31]} \mathrm{Au} @ \mathrm{TiO}_{2}$ and impregnated $\mathrm{Au} / \mathrm{TiO}_{2}(\mathrm{~b})$ samples presented various $\mathrm{CO}$ coordination sites: i) a band centered at 2174-2166 $\mathrm{cm}^{-1}$ 50 resembled the band obtained for the $\mathrm{TiO}_{2}$ (b) support; ii) a small band located at $2075 \mathrm{~cm}^{-1}$ was assigned to $\mathrm{CO}$ adsorbed on low coordinated $\mathrm{Au}^{\circ}$ species; iii) a band centered at 2114-2115 $\mathrm{cm}^{-1}$ and possibly a shoulder at $2127 \mathrm{~cm}^{-1}$ detected only for $\mathrm{Au} @ \mathrm{TiO}_{2}$ were assigned to $\mathrm{CO}$ adsorbed on slightly positively charged gold 55 atoms, $\mathrm{Au}^{\delta+}$, characteristic of Au-O-Ti bonds at the metal-support interface. ${ }^{[29-31]} \mathrm{Au} @ \mathrm{TiO}_{2}(\mathrm{~b})$ displayed just this last unique and well defined coordination site characterized by a band located at $2119 \mathrm{~cm}^{-1}$.

The water gas shift (WGS) reaction was also studied using the ${ }_{60} \mathrm{Au} @ \mathrm{TiO}_{2}$ (b) catalyst. For this reaction, the calculated turnover frequency value after $6 \mathrm{~h}$ reaction at $250{ }^{\circ} \mathrm{C}$ was $6.8 \cdot 10^{7}$ $\mathrm{molH}_{2} / \mathrm{molAu} \cdot \mathrm{s}$. This result confirmed that nanometric gold nanoparticles within $\mathrm{Au} @ \mathrm{TiO}_{2}(\mathrm{~b})$ had optimal size for the water-gas shift reaction. ${ }^{[32-34]}$

\section{Conclusions}

A general procedure to prepare high surface area materials with highly dispersed and accessible embedded catalytic nanoparticles was described. The use of organic spacers as linkers between $\mathrm{Ti}$ 70 atoms allowed producing hybrid organic-inorganic structures with tuned porosity. The final mesoporous materials efficiently blocked the aggregation and growth of the gold nanoparticles, minimizing their sintering during the calcination treatment and increasing the interaction strength between the metal 75 nanoparticles and the oxide support. The good accessibility of gold nanoparticles in these materials was demonstrated by the high $\mathrm{CO}$ to $\mathrm{CO} 2$ conversion values obtained at low temperatures. DRIFT spectroscopy showed a well-defined and specific coordination sites on $\mathrm{Au} @ \mathrm{TiO}_{2}(\mathrm{~b})$ catalyst related to $\mathrm{Au}^{\delta+}$ species 80 resulting from $\mathrm{Au}-\mathrm{O}-\mathrm{Ti}$ interactions at the metal support interface.

The same strategy can be used to prepare other mesoporous supports starting from the corresponding alkoxides, e.g. $\mathrm{CeO}_{2}$, $\mathrm{Fe}_{2} \mathrm{O}_{3}, \mathrm{Al}_{2} \mathrm{O}_{3}$. At the same time other metal nanoparticles can be ${ }_{85}$ introduced in these materials. The only requirement is the proper functionalization of their surface. This opens the door to produce a large variety of catalytic materials containing highly dispersed and accessible metal nanoparticles with controlled size, shape and composition prepared by colloidal synthesis techniques.

\section{${ }_{90}$ Acknowledgements}

The research was supported by the European Regional Development Funds and the Spanish MICINN projects CSD2009-00050, MAT2011-29020-C02-01 and Severo Ochoa Excellence Program SEV-2012-0267.

\section{Notes and references}

${ }^{a}$ Catalonia Institute for Energy Research, IREC, Sant Adrià del Besos, Barcelona, 08930, Spain

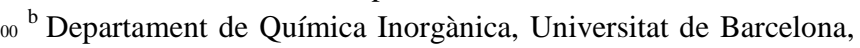
Barcelona, 08028, Spain 
Departament d'Electrònica, Universitat de Barcelona, Barcelona, 08028, Spain

${ }^{d}$ Instituto de Tecnología Química (UPV-CSIC), Universidad

Politécnica de Valencia, Avenida de los Naranjos s/n 46022 5 Valencia, Spain.

Corresponding author: acabot@irec.cat ; acorma@itq.upv.es

1. C. J. Jia, F. Schüth, Phys. Chem. Chem. Phys., 2011, 13, 2457-2487.

102 T. Herranz, X. Deng, A. Cabot, J. Guo, M. Salmeron, J. Phys. Chem. B., 2009, 113, 10721-10727.

3. T. Herranz, X. Deng, A. Cabot, P. Alivisatos, Z. Liu, G. Soler-Illia, M. Salmeron, Catal. Today, 2009, 143, 158166.

15 4. T. Herranz, X. Deng, A. Cabot, Z. Liu, M. Salmeron, J. Catal., 2011, 283, 119-123.

5. C. Flox, J. Rubio-García, R. Nafria, R. Zamani. M. Skoumal. T. Andreu, J. Arbiol, A. Cabot, J. R. Morante, Carbon., 2012, 50, 2372-2374.

20 6. G. Budroni, A. Corma, Angew. Chem. Int. Ed., 2006, 45, 3328-3331.

7. G. Budroni, A. Corma, H. García, A. Primo, J. Catal., 2007, 251, 345-353.

8. B. Rodríguez-González, V. Salgueiriño-Maceira, F. 25 García-Santamaría, L. M. Liz-Marzán., Nano Lett., 2002, 2, 471-473.

9. Y. Kobayashi, M. A. Correa-Duarte, L. M. Liz-Marzán, Langmuir, 2001, 17, 6375-6379.

10. M. Sabo, W. Böhlmann, S. Kaskel, J. Mater. Chem., 2006, 16, 2354.

11. X. Li, X. Liu, Y. Yang, J. Zhao, C. Li, Q. Yang, J. Mater. Chem., 2012, 22, 21045-21050.

12. N. M. Wichner, J. Beckers, G. Rothenberg, H. Koller, J. Mater. Chem., 2010, 20, 3840-3847.

35 13. S. Hausdorf, J. Wagler, R. Mossig, F. O. R. L, Mertens, J. Phys. Chem. A., 2008, 112, 7567-7576.

14. S. Hausdorf, F. Baitalow, J. Seidel, F. O. R. L. Mertens, J. Phys. Chem. A., 2007, 111, 4259-4266.

15. M. Dan-Hardi, C. Serre, T. Frot, L. Rozes, G. Maurin, C. Sanchez, G. Férey, J. Am. Chem. Soc., 2009, 131, 1085710859 .

16. S. W. Boettcher, M. H. Bartl, J. G. Hu, G. D. Stucky, J. Am. Chem. Soc., 2005, 127, 9721-9730.

17. P. Scherrer, Göttinger Nachrichten, 1918, 2, 90.

45 18. J. C. Fierro-Gonzalez, B. C. Gates, Chem. Soc. Rev., 2008, 37, 2127.

19. Z. Ma, S. Dai, Nano Res., 2011, 4, 3-32.

20. J. C. Fierro-Gonzalez, B. C. Gates, Catal. Today, 2007, 122, 201-210.

${ }_{50}$ 21. K. S. W. Sing, Pure Appl. Chem., 1985, 57, 603-619.

22. V. Meynen, P. Cool, E. F. Vansant, Microporous Mater., 2009, 125, 170-223.

23. J. J. Pietron, R. M. Stroud, D. R. Rolison, Nano Lett., 2002, 2, 545-549.

${ }_{55} 24$ H. Zhu, Z. Ma, S. H. Overbury, S. Dai, Catal. Lett., 2007 116, 128-135.

25. Y. Denkwitz, J. Geserick, U. Hörmann, V. Plzak, U. Kaiser, N. Hüsing, R. J. Behm, Catal. Lett., 2007, 119, 199-208.

${ }_{60} 26$. R. Zanella, V. Rodríguez-González, Y. Arzola, A. Moreno-Rodriguez, ACS Catal., 2012, 2, 1-11.
27. S. Carrettin, P. Concepción, A. Corma, A. J. M. López Nieto, V. F. Puntes, Angew. Chem. Int. Ed., 2004, 43, 2538-2540.

${ }_{65} 28$. M. M. Schubert, S. Hackenberg, A. C van Veen, M. Muhler, V. Plzak, R. J. Behm, J. Catal., 2001, 197, 113122.

29. M. Boronat, P. Concepción, A. Corma, J. Phys. Chem. C., 2009, 113, 16772-16784.

70 30. I. X. Green, W. Tang, M. Neurock, J. T. Yates, Science, 2011, 333, 736-739.

31. M. Raphulu, J. McPherson, E. Van der Lingen, J. Anderson, M. Scurrell, Gold Bulletin, 2010, 43, 334-344.

32. T. Si, J. Tao, J. Evans, J. B. Park, L. Barrio, J. C. Hanson, 75 Y. Zhu, J. Hrbek, J. A. Rodriguez, J. Phys. Chem., 2012, 116, 23547-23555.

33. M. Yang, L. F. Allard, M. Flytzani-Stephanopoulos, J. Am. Chem. Soc., 2013, 135, 3768-3771.

34. J. Wang, V. F. Kispersky, N. W. Delgass, F. H. Ribeiro, J. Catal., 2012, 289, 171-178. 